\title{
ENSEÑANZA BÁSICA EN CHILE: LAS ESCUELAS QUE QUEREMOS ${ }^{1,2}$
}

\author{
Alfredo Gaete ${ }^{3}$ y Cristián Ayala
}

\begin{abstract}
RESUMEN
El reporte presenta los resultados de un estudio de opinión realizado en el mes de junio de 2013, cuyo objetivo central fue caracterizar las escuelas básicas que a la ciudadanía le gustaría que hubiese en Chile. Se encontró una tendencia a concebir la educación de calidad muy dependiente de la calidad del profesorado; a preferir un currículo único y centralizado (a cargo del Ministerio de Educación), antes que uno confeccionado a nivel local; y a esperar de la enseñanza básica un proceso formativo que apunte al desarrollo integral de los estudiantes, considerando aspectos tales como la autoestima, la responsabilidad y la buena convivencia (lo que revela un notorio contraste entre lo que la ciudadanía espera y lo que de hecho sucede en la mayoría de nuestras escuelas, las cuales están centradas en los aspectos cognitivo-intelectuales). Se proponen distintas explicaciones para la preferencia ciudadana por un currículo único y centralizado y se ahonda en una de ellas (que guarda relación con la construcción de la identidad nacional). También se discute el papel que tiene la voz de la ciudadanía en estas materias y la brecha evidente que hay, en ciertos ámbitos, entre lo que la gente espera de la escuela y lo que de hecho ocurre en ella.
\end{abstract}

Palabras clave: calidad de la educación, ciudadanía y educación, currículo escolar, enseñanza básica, fines de la educación, objetivos de la enseñanza básica.

\section{PRIMARY EDUCATIONINCHILE: THE SCHOOLS THAT WE WANT}

\section{ABSTRACT}

This report presents the results of an opinion study carried out in June, 2013. Its central aim was to characterize the primary schools that citizens would like to have in Chile. A tendency was found to conceive of education quality as very dependent upon teacher quality; to prefer a unique, centralized curriculum (in charge of the Ministry of Education) over one developed at a local level; and to expect that primary education will provide a formative process orientated towards the holistic development of students, including such aspects as self-esteem, responsibility, and living together (which reveals a clear contrast between what citizens expect from our schools and what in fact happens in most of them, given the emphasis placed on the cognitive-intellectual aspects). We present different explanations for the citizens' preference for a unique, centralized curriculum, focusing on one that appeals to issues related to the construction of national identity. We also discuss the role of the citizens' voice in these matters as well as the evident gap that exists in certain areas between what people expect from, and what actually happens in, schools.

Keywords: education quality, citizenship and education, school curriculum, primary education, the goals of education, the objectives of primary education.

1 Este artículo reporta resultados de un estudio financiado por CONICYT: Proyecto FONDECYT No 11121589

2 Estamos en deuda con Martín Bascopé por sus excelentes recomendaciones y comentarios a una versión anterior de este trabajo. También agradecemos a los revisores de la revista por sus valiosas indicaciones.

3 Pontificia Universidad Católica de Chile, Campus Villarrica, Villarrica, Chile. Contacto: agaetes@uc.cl

4 Dirección de Estudios Sociales del Instituto de Sociología de la Pontificia Universidad Católica de Chile, Santiago, Chile. 


\section{Introducción}

En el discurso público desde 2009 hasta la fecha, y en el académico durante las últimas dos décadas, la calidad de la educación ha sido un elemento recurrente que ha llegado a constituirse en uno de los ejes del debate educativo en Chile (véase, por ejemplo, Abarca et al., 2009; Alfaro et al., 2011; Centro de Políticas Públicas, 2012; Comité Técnico Asesor del Diálogo Nacional sobre la Modernización de la Educación Chilena, 1994; Cox, 2003; Eyzaguirre y Le Foulon, 2001; Falabella y García-Huidobro, 2013; Núñez, 1996; OCDE, 2004; Redondo, Descouvières y Rojas, 2004; Valdebenito, 2011). Se asume de manera bastante generalizada, y a lo largo de todo el espectro político, que la calidad debe mejorarse; y quienes tienen hijos en el sistema han manifestado de manera consistente, al menos desde 1996 en adelante, que la calidad de la instrucción académica es uno de los aspectos más importantes a la hora de escoger un colegio (Centro de Estudios Públicos, 2011). De modo que la pregunta de qué se entiende por "calidad" en estos contextos, o al menos cuáles son los criterios en los que la gente se basa para hacer un juicio acerca de esta, resulta de la mayor importancia. ¿Se fijan los padres más en la infraestructura de la escuela o en su cuerpo docente? ¿Más en su proyecto educativo o en el rendimiento de sus alumnos en pruebas estandarizadas? ¿Cuáles de estos y otros aspectos son los que más pesan?

El estudio que aquí reportamos está motivado, en parte, por preguntas como estas, pero tiene un propósito más amplio. Existe en la actualidad bastante consenso en que la escuela debe responder a los desafíos sociales contemporáneos. Como señalara Jerome Bruner (1996), "aquello que resolvemos hacer en la escuela solo tiene sentido cuando se lo considera en el contexto más amplio de lo que la sociedad intenta conseguir a través de su inversión educacional en los jóvenes" (p. ix). Es cierto que mucho de lo que ocurre en el proceso de enseñanza formal depende -y así debe ser- de decisiones profesionales tomadas por profesores y otros agentes educativos, pero la escuela no puede ser un sistema cerrado. En particular, y dado el papel fundamental que tiene esta en la formación de ciudadanos (Dewey, 2007; Levinson \& Holland, 1996; Peña, 2013; Tedesco, 2000), todos los miembros de la sociedad tienen derecho a pronunciarse respecto 
de qué deben aprender los niños durante su escolarización, al menos en el sentido de cuál es el ideal de persona que ha de inspirar y guiar la tarea educativa. Establecer los fines de la educación, sobre todo los de la educación pública, no es prerrogativa ni de los educadores ni de los políticos ni de ningún grupo específico de ciudadanos, sino de la sociedad en su conjunto.

Dicho de otro modo, la ciudadanía toda tiene el derecho de participar en la decisión de qué modelo de persona y de sociedad ha de inspirar la formación impartida en las escuelas, aun cuando pueda no estar consciente de ese derecho en la actualidad (más adelante retomamos este punto). Esto no quiere decir que la "opinión pública" tenga fuerza de ley en estas materias. Pero las expectativas que chilenas y chilenos tenemos respecto de nuestro sistema escolar, especialmente aquellas asociadas a sus fines últimos, constituyen parte importante de lo que debiera tenerse en cuenta al momento de diseñar políticas públicas en educación. Las decisiones en esta área no son asuntos meramente técnicos: dependen en buena medida de lo que la gente considera que es deseable, valioso y bueno.

El siguiente reporte presenta los resultados de un estudio de opinión realizado en el mes de junio de 2013, cuyo objetivo central fue precisamente caracterizar la escuela básica que a la ciudadanía le gustaría que hubiera en Chile. Entre otras cosas, y por las razones que ya apuntamos, nos interesaba saber en virtud de qué criterios las personas juzgan la calidad de la enseñanza básica. También queríamos hacernos una idea de cuáles de los Objetivos Generales de la Educación Básica (expresados en la Ley General de Educación) se consideran más importantes. Después de todo, la priorización de áreas y contenidos es una tarea habitual y necesaria tanto para el curriculista como para el diseñador de políticas, el gestor educacional y, por cierto, el enseñante. Disponer de un listado de objetivos no es en sí mismo muy útil si no se dispone, además, de una pauta de prioridades, sobre todo cuando los objetivos son muchos y muy ambiciosos (como es el caso). En esta línea, también intentamos testear lo que se piensa respecto de algunas tensiones -incluyendo algunas "antinomias" en el sentido de Brunner (1996)- a las que los agentes educativos se pueden ver enfrentados al momento de tomar 
decisiones acerca de lo que la enseñanza básica debiese privilegiar o enfatizar. Sabemos que el tema de los fines de la educación es complejo y presenta una variedad de dificultades (véase, por ejemplo, Bruner, 1996; Delval, 1996; MacBeath, 2012; Falabella y García-Huidobro, 2013), pero esperamos que estos resultados y las consideraciones que hacemos a partir de ellos aporten en algún grado, por pequeño que sea, al desentrañamiento y comprensión de esta compleja problemática.

\section{Metodología}

\subsection{Participantes}

El grupo objetivo estuvo compuesto por hombres y mujeres mayores de 18 años residentes de grandes centros urbanos del país. Se eligió este grupo para tener una representación no solo de quienes tienen hijos en el sistema escolar, sino de los chilenos con derecho a voto en general. Desafortunadamente, por razones técnicas fue necesario restringir la muestra al sector urbano lo que sin duda implica un sesgo importante.

\subsection{Técnica}

Se utilizó una encuesta telefónica que tuvo como marco muestral los hogares urbanos que disponen de teléfono fijo en 61 comunas del país ${ }^{5}$. Dentro de esos hogares, se entrevistó a hombres y mujeres mayores de 18 años y residentes de esos hogares, excluyendo al servicio doméstico.

La elección de entrevistados fue probabilística para el caso de los hogares, mediante un proceso de selección aleatoria a partir del listado de teléfonos residenciales por comuna. Dentro del hogar se fijaron cuotas por género y grupo etario para los individuos. La asignación de las cuotas dentro de la comuna fue aleatoria.

5 Comunas del Gran Santiago (34), capitales regionales y otras ciudades de más de 60.000 habitantes. La razón por la cual se restringió el estudio a sectores mayoritariamente urbanos es que ello permitía generar un marco de teléfonos fijos suficientemente robusto para contactar aleatoriamente los hogares. 


\subsection{Instrumento}

Se realizó una encuesta telefónica con 33 preguntas $^{6}$ que incluía los siguientes temas:

- Calidad de la educación básica.

- Rol/responsabilidad del Estado y la familia en la educación básica.

- Objetivos de la enseñanza básica.

- Tensiones en la escuela.

Las preguntas hacían referencia a la educación básica en Chile, sin explicitar ningún tipo de dependencia. La idea era no constreñir las respuestas a las condiciones actuales de la educación, en el entendido de que el punto central del estudio es caracterizar la básica que la ciudadanía desearía tener -la escuela "ideal", si se quiere- y no la básica que existe de hecho.

En el proceso de confección del instrumento participaron, además de los dos autores, dos comités académicos que trabajaron de manera independiente (sin contacto entre ellos). El proceso fue liderado por los autores, quienes produjeron una primera versión de la encuesta y fueron haciendo modificaciones sobre la base de revisiones realizadas por los comités en diversas instancias.

\subsection{Diseño y tamaño de la muestra}

La muestra fue estratificada por regiones, probabilística en el caso de los hogares, para terminar fijando cuotas de respuesta por sexo y edad dentro de los hogares seleccionados. La encuesta fue respondida por 1.515 personas en total, entre el 29 de mayo y el 3 de junio de 2013. Para presentar los resultados, los casos obtenidos fueron ponderados según sexo, edad, región y segmento socioeconómico ${ }^{7}$, usando el método raking (esto es, ajustando la muestra según la distribución marginal de las variables de la población objetivo). Como parámetros

6 La encuesta completa tuvo una duración promedio de 21,6 minutos y una mediana de 19 minutos.

7 Para la clasificación del nivel socioeconómico de los encuestados se utilizó el cruce entre el nivel educacional del jefe de hogar y su profesión. La pregunta directa por nivel de ingreso del hogar en una entrevista telefónica tiene una alta tasa de subdeclaración y omisión, lo que impide clasificar a la totalidad de los encuestados en uno de los segmentos necesarios para la ponderación. 
poblacionales se utilizaron datos del Censo 2002, proyectados por el INE a $2010^{8}$.

\subsection{Distribución de la muestra}

En la Tabla 1 se detalla la muestra real obtenida y la distribución resultante luego de ponderar los casos. La muestra lograda sobrerrepresentaba a las mujeres (59\% versus $41 \%$ de hombres para una distribución que debiera ser $52 \%$ versus $48 \%$, respectivamente) y personas de mayor edad (la muestra tiene $30 \%$ de personas entre $18 \mathrm{y}$ 34 años respecto del parámetro poblacional estimado de 40\%). Estas diferencias se deben a la mayor cooperación de mujeres y personas de mayor edad a participar en estudios de opinión, además de ser más fácilmente contactables por llamadas al hogar. Esas diferencias fueron corregidas mediante ponderadores de ajuste basadas en las proyecciones poblacionales de INE a julio de 2013.

8 Si suponemos una muestra probabilística formada mediante un sistema de elección aleatorio simple, el margen de error de los resultados para una proporción con varianza máxima sería de $\pm 2,5$ puntos con un $95 \%$ de confianza. 
Tabla 1: Distribución de la muestra según segmentos de sexo-edad y zona geográfica

\begin{tabular}{l|c|c|c|c}
\hline Segmentos & $\begin{array}{c}\text { Distribución } \\
\text { poblacional \% }\end{array}$ & $\begin{array}{c}\text { Casos no } \\
\text { ponderados }\end{array}$ & $\begin{array}{c}\text { Distribución no } \\
\text { ponderada }\end{array}$ & $\begin{array}{c}\text { Distribución } \\
\text { ponderada }\end{array}$ \\
\hline Hombres entre 18 y 34 años & $20 \%$ & 203 & $13 \%$ & $20 \%$ \\
\hline Hombres entre 35 y 54 años & $18 \%$ & 222 & $15 \%$ & $18 \%$ \\
\hline Hombres de 55 años o más & $9 \%$ & 198 & $13 \%$ & $9 \%$ \\
\hline Mujeres entre 18 y 34 años & $20 \%$ & 254 & $17 \%$ & $20 \%$ \\
\hline Mujeres entre 35 y 54 años & $20 \%$ & 375 & $25 \%$ & $20 \%$ \\
\hline Mujeres de 55 años o más & $12 \%$ & 263 & $17 \%$ & $12 \%$ \\
\hline Zona Norte & $11 \%$ & 175 & $11 \%$ & $11 \%$ \\
\hline Zona Centro & $21 \%$ & 335 & $22 \%$ & $21 \%$ \\
\hline Zona Sur & $27 \%$ & 400 & $27 \%$ & $27 \%$ \\
\hline Zona Metropolitana & $41 \%$ & 605 & $40 \%$ & $41 \%$ \\
\hline Total & $100 \%$ & 1.515 & $100 \%$ & $100 \%$ \\
\hline
\end{tabular}

La muestra se estratificó según la distribución geográfica de la población de las 61 comunas elegidas. Así, la distribución muestral se asemeja bastante a su parámetro poblacional. Como puede verse en la Tabla 2, la mayor diferencia es un punto porcentual en la zona centro y Metropolitana ${ }^{9}$.

\section{Resultados}

Presentamos a continuación los principales resultados del estudio. Hemos omitido todos los resultados de aquellas preguntas cuya formulación nos hacía dudar de si los participantes estaban efectivamente respondiendo en virtud de su escuela ideal o de las que tenemos de hecho ${ }^{10}$. Esto, para no contaminar la representación de lo que la ciudadanía quisiera o esperaría de la educación básica con aquello que, a su juicio, ya existe o es el caso.

9 La zona norte abarca las regiones 15, 1, 2, 3 y 4. La zona centro contiene las regiones 5, 6 y 7. La zona sur incluye las regiones $8,9,10,11,12$ y 14. Por su cantidad de población, la zona Metropolitana se forma solo con los entrevistados de la Región Metropolitana.

10 Desafortunadamente, y pese a que la encuesta fue sometida a diversas revisiones tanto por los autores como por distintos comités académicos, la excesiva ambigüedad de algunas de las preguntas fue detectada solo a posteriori (después de la aplicación), durante el proceso de interpretación de resultados. 


\subsection{Profesores: principal índice de calidad}

Ante la pregunta (abierta): "¿Qué elementos tiene que mostrar una escuela para decir que es de calidad?", el elemento al que más se aludió fue, por lejos, la calidad de los profesores, ya sea de manera directa o mediante una referencia a su preparación. Con un número mucho menor de menciones destacan también la infraestructura y el programa educativo. Por otro lado, es notoriamente bajo el porcentaje de casos en que se refieren los puntajes SIMCE y PSU (Gráfico 1).

Gráfico 1: Elementos que debe mostrar una escuela de calidad

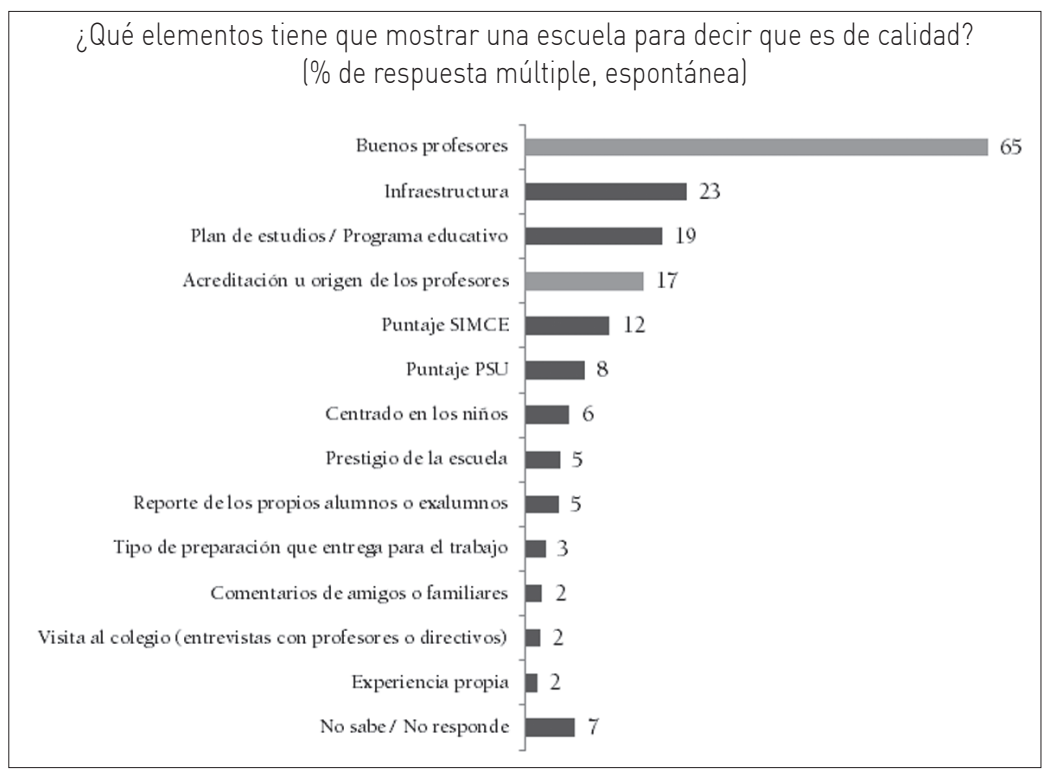

En el segmento socioeconómico bajo se apunta aún más a los profesores. En cambio, los puntajes SIMCE y PSU fueron más mencionados en los segmentos medio y alto (pero siguen siendo relativamente poco aludidos en comparación con los profesores, la infraestructura y el programa). Estas y otras diferencias estadísticamente significativas al interior de distintos grupos (segmento socioeconómico, género y rango etario) se presentan en la Tabla 2. 
Tabla 2: Elementos de una escuela de calidad según NSE, sexo y edad

\begin{tabular}{|c|c|c|c|c|c|c|c|c|c|}
\hline \multirow[b]{2}{*}{$\begin{array}{l}\text { Elementos } \\
\% \text { de respuesta múltiple }\end{array}$} & \multirow[b]{2}{*}{ Total } & \multicolumn{3}{|c|}{ Nivel socioeconómico } & \multicolumn{2}{|c|}{ Sexo } & \multicolumn{3}{|c|}{ Edad } \\
\hline & & $\begin{array}{l}\text { Alto } \\
\text { (A) }\end{array}$ & $\begin{array}{c}\text { Medio } \\
\text { (B) }\end{array}$ & $\begin{array}{l}\text { Bajo } \\
\text { (C) }\end{array}$ & $\begin{array}{c}\text { Hombre } \\
\text { (A) }\end{array}$ & $\begin{array}{l}\text { Mujer } \\
\text { (B) }\end{array}$ & $\begin{array}{c}18-34 \\
\text { (A) }\end{array}$ & $\begin{array}{c}35-54 \\
\text { (B) }\end{array}$ & $\begin{array}{l}55+ \\
\text { (C) }\end{array}$ \\
\hline Buenos profesores & 65 & 61 & 61 & $70^{\mathrm{AB}}$ & 65 & 65 & 64 & 64 & 69 \\
\hline Infraestructura & 23 & $28^{c}$ & $25^{\mathrm{c}}$ & 18 & $26^{\mathrm{B}}$ & 20 & 23 & 24 & 19 \\
\hline $\begin{array}{l}\text { Plan de estudios / } \\
\text { Programa educativo }\end{array}$ & 19 & 20 & 21 & 18 & 18 & 20 & 20 & 20 & 16 \\
\hline $\begin{array}{l}\text { Acreditación u origen de } \\
\text { los profesores }\end{array}$ & 17 & 18 & 16 & 16 & 18 & 16 & 19 & 14 & 17 \\
\hline Puntaje SIMCE & 12 & $18^{c}$ & $15^{\mathrm{C}}$ & 6 & 12 & 12 & $14^{c}$ & $13^{c}$ & 7 \\
\hline Puntaje PSU & 8 & $14^{c}$ & $10^{c}$ & 4 & 8 & 8 & 8 & 10 & 6 \\
\hline Centrado en los niños & 6 & 6 & 5 & 7 & 5 & $8^{A}$ & 7 & 6 & 6 \\
\hline Prestigio de la escuela & 5 & 5 & 4 & 5 & 5 & 5 & $7^{\mathrm{B}}$ & 3 & 5 \\
\hline $\begin{array}{l}\text { Reporte de los propios } \\
\text { alumnos o exalumnos }\end{array}$ & 5 & 4 & 5 & 5 & 5 & 5 & 5 & 4 & 6 \\
\hline $\begin{array}{l}\text { Tipo de preparación que } \\
\text { entrega para el trabajo }\end{array}$ & 3 & 3 & 3 & 3 & 4 & 2 & 3 & 2 & 3 \\
\hline $\begin{array}{l}\text { Comentarios de amigos } 0 \\
\text { familiares }\end{array}$ & 2 & 3 & 2 & 3 & 2 & 3 & 3 & 3 & 2 \\
\hline $\begin{array}{l}\text { Visita al colegio } \\
\text { (entrevistas con } \\
\text { profesores o directivos) }\end{array}$ & 2 & 2 & 1 & 3 & 1 & 3 & 2 & 3 & 1 \\
\hline Experiencia propia & 2 & 2 & 1 & 2 & 2 & 2 & 2 & 1 & 1 \\
\hline No sabe / No responde & 7 & 4 & 8 & $9 \mathrm{~A}$ & 7 & 7 & 6 & 6 & 10 \\
\hline Total & 100 & 100 & 100 & 100 & 100 & 100 & 100 & 100 & 100 \\
\hline
\end{tabular}

\subsection{Currículo centralizado e importancia de la familia}

Respecto de los "responsables" de la educación básica, primero se indagó en el grado de centralización del currículo ${ }^{11}$ (entre un polo donde las decisiones curriculares se toman centralizadamente para todos los establecimientos y otro donde cada uno decide su propio currículo) y luego en la responsabilidad que la familia y la escuela debiesen tener en aquello que aprenden los niños. Ante la pregunta por lo primero,

11 Aun cuando los especialistas usan "plan de estudios" y "currículo" para referirse a cosas distintas, aquí los tratamos como sinónimos. De hecho, dado que las personas consultadas pertenecen a la población general, asumimos que preguntarles por el plan de estudios era más apropiado, considerando que es una expresión menos técnica que currículo. 
alrededor de dos tercios de los encuestados se inclina por un plan fijo y único para todo el país. Se nota, además, una propensión mayor en esta línea en niveles socioeconómicos medios y bajos, así como en personas mayores de 35 años. Sin embargo, más allá de estas variaciones, la tendencia general se repite en todos los niveles socioeconómicos, en todos los grupos etarios y en ambos sexos (Gráfico 2).

Gráfico 2: Preferencia por un currículo fijo y único o que cada colegio pueda tener uno propio según NSE, sexo y edad

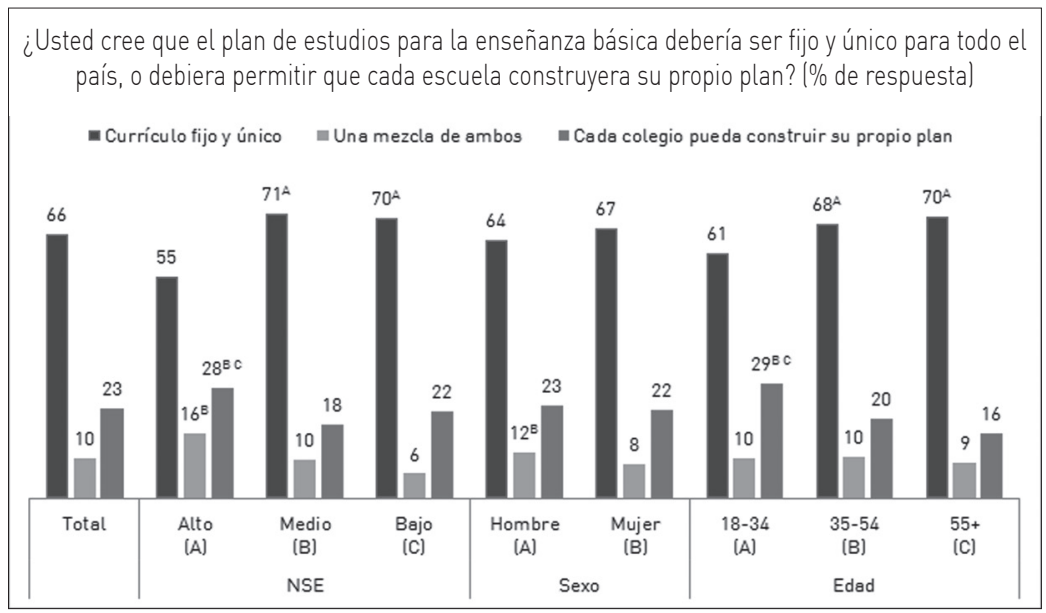

Diferencias significativas al $95 \%$ de confianza.

Por otra parte, fueron muy pocos los encuestados que desafiaron la extrema polarización de la pregunta (apenas el 10\%), apuntando a una mezcla entre decisiones centrales y locales.

Cabe señalar que si separamos estos resultados por zona geográfica, la opinión favorable al plan fijo y único sigue siendo mayoritaria. Hay una diferencia significativa entre el porcentaje que favorece esa opción en la Región Metropolitana (70\%) y el registrado en la zona sur (61\%), pero en ambos casos la mayoría de los encuestados sigue optando por el plan fijo y único.

A la pregunta (abierta) de quién debería determinar lo que tienen que aprender los niños durante la enseñanza básica, una 
clara mayoría señala que el Gobierno ${ }^{12}$. También se menciona a los profesores y a la familia. La ciudadanía obtiene una muy escasa frecuencia de alusiones. Es interesante asimismo que casi no se observen diferencias significativas entre los distintos grupos (Tabla 3).

Tabla 3: Organismos e instituciones encargadas de determinar lo que se debe enseñar a niños en la enseñanza básica según NSE, sexo y edad

\begin{tabular}{|c|c|c|c|c|c|c|c|c|c|}
\hline \multirow[b]{2}{*}{$\begin{array}{l}\text { Organismos } \\
\text { \% de respuesta múltiple }\end{array}$} & \multirow[b]{2}{*}{ Total } & \multicolumn{3}{|c|}{ Nivel socioeconómico } & \multicolumn{2}{|c|}{ Sexo } & \multicolumn{3}{|c|}{ Edad } \\
\hline & & $\begin{array}{l}\text { Alto } \\
\text { (A) }\end{array}$ & $\begin{array}{l}\text { Medio } \\
\text { (B) }\end{array}$ & $\begin{array}{l}\text { Bajo } \\
\text { (C) }\end{array}$ & $\begin{array}{c}\text { Hombre } \\
\text { (A) }\end{array}$ & $\begin{array}{l}\text { Mujer } \\
\text { (B) }\end{array}$ & $\begin{array}{c}18-34 \\
\text { (A) }\end{array}$ & $\begin{array}{c}35-54 \\
(B)\end{array}$ & $\begin{array}{l}55+ \\
\text { (C) }\end{array}$ \\
\hline $\begin{array}{l}\text { Estado/Gobierno/ } \\
\text { Ministerio de Educación }\end{array}$ & 56 & 60 & 57 & 54 & 57 & 56 & 54 & 57 & 60 \\
\hline Los profesores & 36 & 34 & 36 & 36 & 33 & 38 & 36 & 35 & 35 \\
\hline $\begin{array}{l}\text { Familia/padres/ } \\
\text { apoderados }\end{array}$ & 31 & 29 & 31 & 34 & 28 & $34^{A}$ & 30 & 30 & 37 \\
\hline Escuela/colegio & 17 & 18 & 13 & $19^{B}$ & 16 & 19 & 21 & 15 & 15 \\
\hline $\begin{array}{l}\text { La ciudadanía/todos los } \\
\text { chilenos }\end{array}$ & 6 & 6 & 6 & 7 & 8 & 5 & 7 & 6 & 6 \\
\hline Los mismos niños & 2 & 1 & 2 & 2 & 1 & 2 & 1 & 2 & 2 \\
\hline Iglesia & 1 & 0 & 1 & 1 & 1 & 0 & 0 & 1 & 1 \\
\hline No sabe / No responde & 4 & 3 & 5 & 5 & 5 & 3 & 5 & 3 & 4 \\
\hline Total & 100 & 100 & 100 & 100 & 100 & 100 & 100 & 100 & 100 \\
\hline
\end{tabular}

Diferencias significativas dentro de cada segmento se calculan mediante test-z de proporciones de dos colas con un $95 \%$ de confianza.

En cada valor con fondo gris se marca con un superíndice las columnas dentro de su segmento respecto de las que tiene una proporción significativamente mayor.

Más adelante se preguntó sobre la responsabilidad de la familia y de la escuela frente a nueve ámbitos específicos de enseñanza (Gráfico 3). En términos generales, y salvo en lo que respecta a la formación intelectual, la familia se concibe como la responsable principal, junto con un apoyo variable de la escuela. La religión, en un extremo, se percibe como una esfera de responsabilidad eminentemente familiar. Luego hay aspectos como la formación ética o valórica, la educación sexual y económica, y el cuidado físico y mental en los cuales, aunque

12 Incluimos en la categoría "Gobierno", además de las referencias directas, referencias indirectas como "el Ministerio de Educación" o "el Estado". A quienes respondieron "el Estado" se les hizo una pregunta adicional en donde se indagó si se refería a "la ciudadanía" o "al Gobierno". Las respuestas se agruparon a la respuesta general según esa segunda pregunta. 
la familia sigue manteniendo la mayor parte de la responsabilidad, se deja bastante espacio a la escuela como complemento. La política, la convivencia con otros niños y la educación ambiental son ámbitos aún más compartidos (en los que de hecho sube la opción "ambos por igual"). Por último, en el ámbito de la formación intelectual, las personas entrevistadas le entregan mayor preponderancia a la escuela por sobre la familia.

Gráfico 3: Responsabilidad de familia o escuela frente a ámbitos específicos

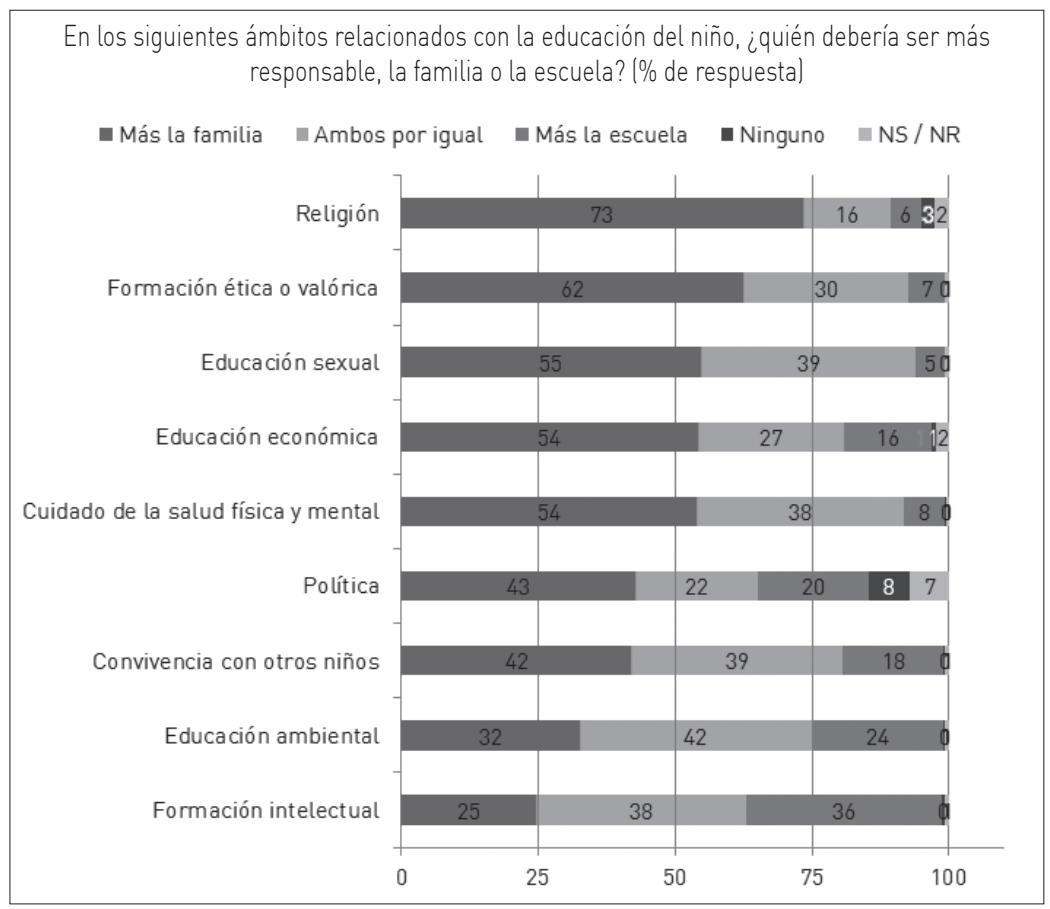

Hubo algunas diferencias por sexo y edad, pero independientemente de ellas ambos sexos y los tres grupos etarios mantuvieron el patrón general de respuesta, al igual que los distintos segmentos socioeconómicos. En la Tabla 4 se muestra que tanto los hombres como las personas entre 18 y 34 años de edad tienden sistemáticamente a entregar mayor responsabilidad a la escuela en la mayoría de los ámbitos evaluados. 
Tabla 4: Relación entre familia y escuela por ámbitos de educación según sexo y edad

\begin{tabular}{|c|c|c|c|c|c|c|c|c|c|}
\hline \multirow[b]{2}{*}{$\begin{array}{l}\text { Ámbitos de la educación } \\
\text { \% de respuesta "Más la } \\
\text { escuela" }\end{array}$} & \multirow[b]{2}{*}{ Total } & \multicolumn{3}{|c|}{ Nivel socioeconómico } & \multicolumn{2}{|c|}{ Sexo } & \multicolumn{3}{|c|}{ Edad } \\
\hline & & $\begin{array}{l}\text { Alto } \\
\text { (A) }\end{array}$ & $\begin{array}{l}\text { Medio } \\
\text { (B) }\end{array}$ & $\begin{array}{l}\text { Bajo } \\
\text { (C) }\end{array}$ & $\begin{array}{c}\text { Hombre } \\
\text { (A) }\end{array}$ & $\begin{array}{l}\text { Mujer } \\
\text { (B) }\end{array}$ & $\begin{array}{c}18-34 \\
\text { (A) }\end{array}$ & $\begin{array}{c}35-54 \\
\text { (B) }\end{array}$ & $\begin{array}{l}55+ \\
\text { (C) }\end{array}$ \\
\hline Formación intelectual & 36 & 37 & 38 & 34 & $39 \mathrm{~B}$ & 33 & $41^{\mathrm{B}}$ & 32 & 33 \\
\hline Educación ambiental & 24 & 23 & 20 & $27^{B}$ & $27^{\mathrm{B}}$ & 21 & $28^{B}$ & 20 & 24 \\
\hline $\begin{array}{l}\text { Convivencia con otros } \\
\text { niños }\end{array}$ & 18 & 20 & 17 & 18 & $23^{B}$ & 14 & $23^{B}$ & 14 & 18 \\
\hline Política & 20 & 17 & 22 & 21 & 22 & 18 & $27^{\mathrm{BC}}$ & 14 & 17 \\
\hline $\begin{array}{l}\text { Cuidado de la salud } \\
\text { física y mental }\end{array}$ & 8 & 8 & 7 & 8 & 9 & 6 & $11^{\mathrm{B}}$ & 4 & 7 \\
\hline Educación económica & 16 & 19 & 16 & 14 & $18^{\mathrm{B}}$ & 14 & $20^{B C}$ & 14 & 11 \\
\hline Educación sexual & 5 & 4 & 5 & 6 & $7^{B}$ & 3 & 5 & 3 & $9^{B}$ \\
\hline $\begin{array}{l}\text { Formación ética o } \\
\text { valórica }\end{array}$ & 7 & 3 & 7 & $9^{A}$ & $8^{B}$ & 5 & 6 & 6 & 8 \\
\hline Religión & 6 & 4 & 4 & 7 & $8^{B}$ & 3 & 7 & 4 & 5 \\
\hline Total & 100 & 100 & 100 & 100 & 100 & 100 & 100 & 100 & 100 \\
\hline
\end{tabular}

\subsection{Predilección por las "habilidades blandas"}

Para indagar en la importancia relativa de los objetivos de la enseñanza básica, se realizaron dos preguntas en las que se pidió a las personas ordenar, del más importante al menos importante, tres aspectos a desarrollar durante este periodo educativo. Estos aspectos estaban asociados con algunos de los Objetivos Generales de la Educación Básica expuestos en la Ley General de Educación. En ambos casos se comparó un aspecto más bien cognitivo (pensamiento lógicomatemático, lectura y escritura) y asociado a asignaturas específicas (Matemáticas y Lenguaje), con disposiciones sociales y emocionales (buena convivencia con otros, responsabilidad, autoestima positiva) y con una habilidad cognitiva más genérica o transversal (pensamiento reflexivo). Frente a la primera tríada (Gráfico 4), apenas uno de cada 10 encuestados (aproximadamente) describe como más importante el pensamiento lógico-matemático. La preferencia por las así llamadas "habilidades blandas" es aquí sencillamente arrolladora. 
Gráfico 4: Objetivos de la enseñanza, primera tríada

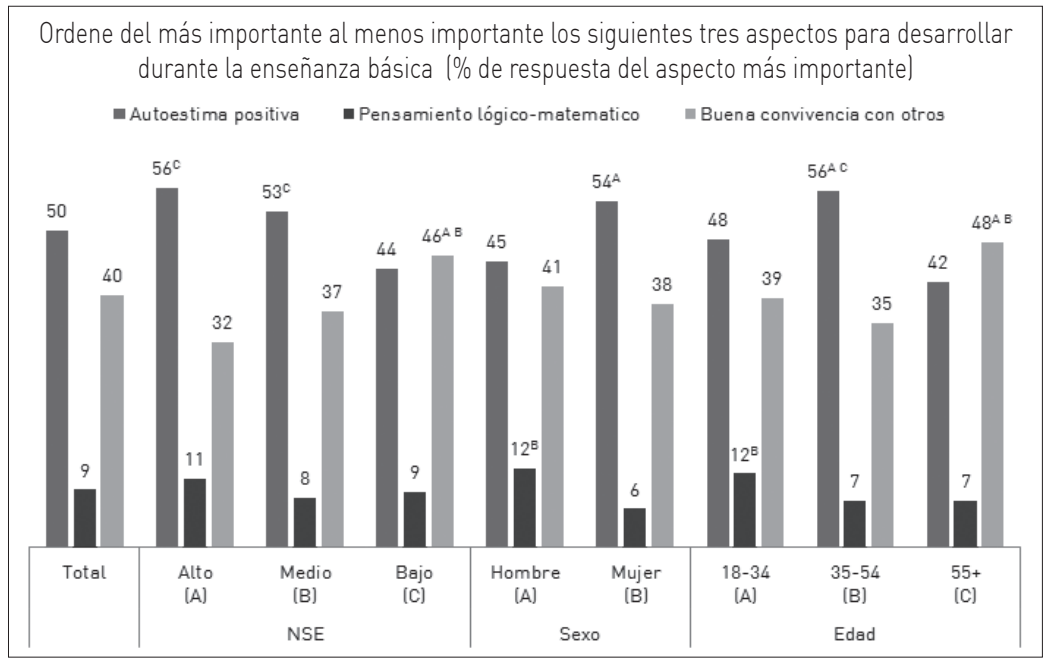

Debe notarse la diferencia en las respuestas según segmento socioeconómico. Mientras que los segmentos alto y medio declaran como más importante la autoestima positiva, para el segmento bajo el objetivo más importante es la buena convivencia con otros. Este es uno de los contados casos en los que alguno de los distintos segmentos se comportó de manera diferente a la tendencia general (no desagregada por segmento).

En la segunda tríada (Gráfico 5), la mayoría muestra predilección por la responsabilidad en primer lugar. Le sigue la lectura y escritura, quedando el pensamiento reflexivo como el menos favorecido. Debe notarse, sin embargo, que las menciones del pensamiento reflexivo como aspecto más importante casi duplican a las menciones del pensamiento matemático y, en contraste con la tendencia general, en el segmento alto superan a las menciones de la lectura y la escritura. 
Gráfico 5: Objetivos de la enseñanza, segunda tríada

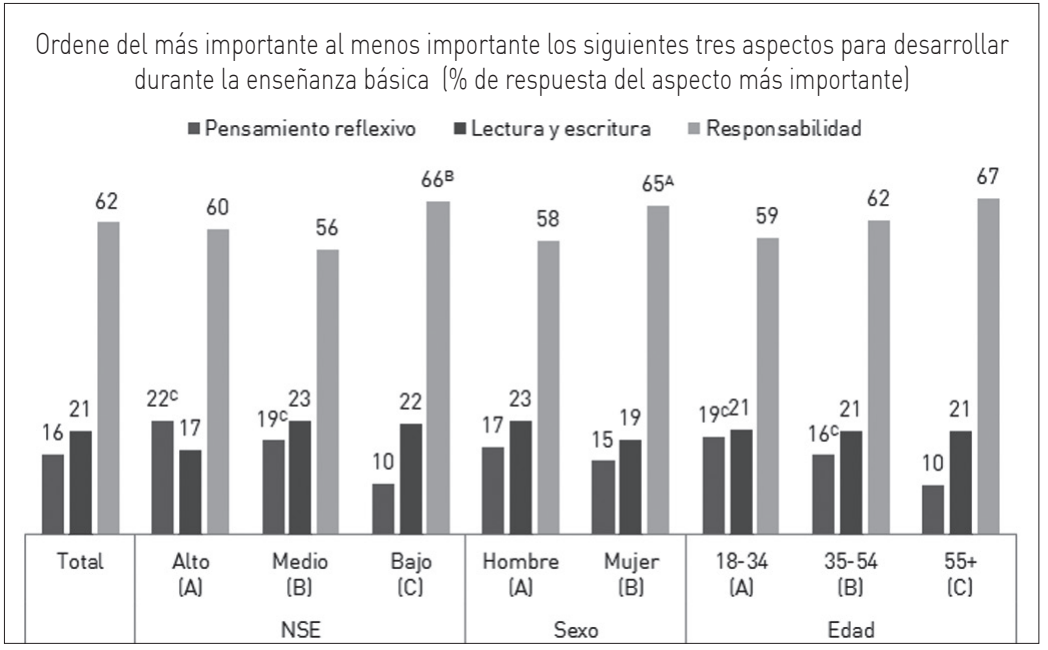

Diferencias basadas en test de significancia al .05 de dos colas. En cada valor se marca con un superíndice el segmento respecto de las que tiene una proporción significativamente mayor.

\subsection{Diversidad social, tradiciones nacionales, autonomía}

A los entrevistados se les pidió que definieran su postura frente a seis tensiones que pueden existir al interior de la escuela básica. Las seis preguntas, presentadas de forma aleatoria a los entrevistados, fueron las siguientes:

- ¿Le parece mejor una escuela cuyos alumnos provengan de familias similares o una escuela en que haya diversidad social?

- ¿La enseñanza básica debiera enfocarse en que los niños entren a la universidad o en mostrar diferentes caminos en los que la universidad es solo uno de ellos?

- ¿La escuela debería fomentar más la enseñanza de la cultura tradicional chilena en general o de tradiciones específicas de la zona en que se encuentra cada escuela?

- En su opinión, ¿durante la enseñanza básica las clases deberían fomentar más la disciplina y el orden o la autonomía y la creatividad?

- ¿Las clases deberían enfocarse más en la enseñanza de las ciencias o en ámbitos más artísticos?

- ¿Las clases deberían fomentar más el desarrollo intelectual o el desarrollo social y emocional de los niños? 
El resumen de las respuestas frente a ambos polos puede verse en el Gráfico 6.

Gráfico 6: Tensiones en la escuela

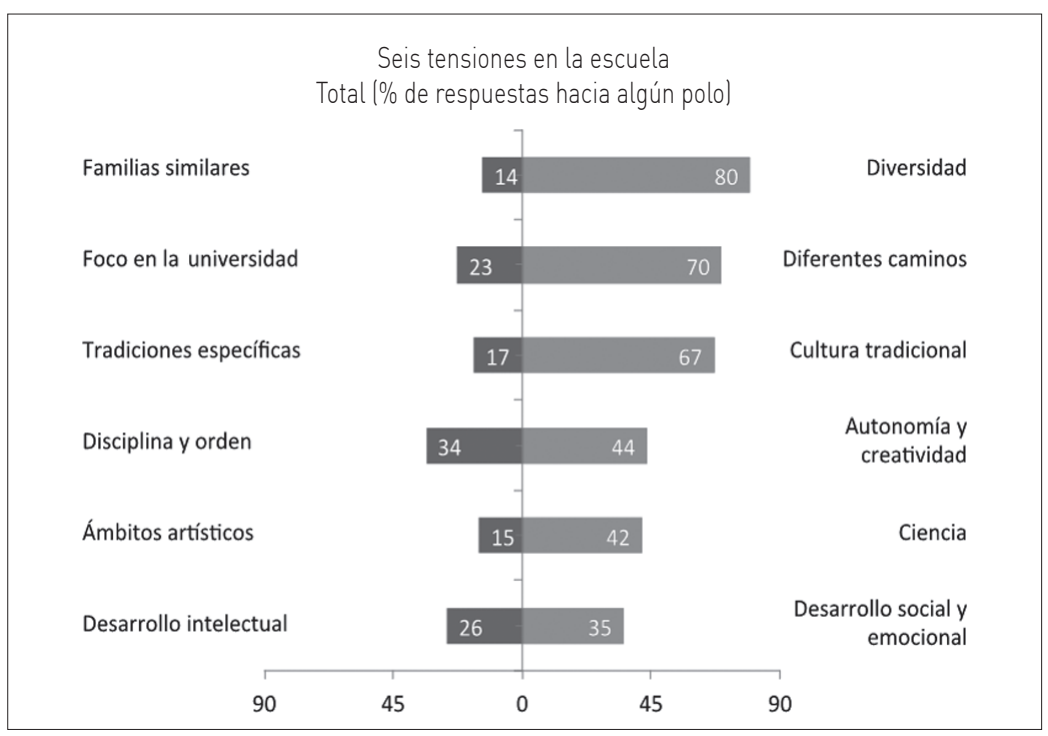

Hay tres tensiones que se deciden mayoritariamente hacia uno de los polos. La ciudadanía parece inclinarse fuertemente hacia una escuela básica con diversidad social, que muestre diferentes caminos de desarrollo personal (más que estar focalizada en el ingreso a la universidad) y que fomente la enseñanza de la cultura tradicional chilena (más que de tradiciones locales o específicas de cada zona). Respecto de esto último, se revisaron las respuestas por zona geográfica: en todas tiene mayoría la preferencia por la cultura tradicional chilena, aunque las zonas centro $(71 \%)$ y Metropolitana (70\%) difieren significativamente de las zonas norte y sur (ambas con $61 \%)$.

\subsection{Tendencia al equilibrio y diferencias entre grupos}

Las otras tensiones se resolvieron de manera más equilibrada. Respecto de la elección entre disciplina/orden y autonomía/creatividad, el total de los entrevistados se inclina levemente por el segundo polo. 
Sin embargo, más de un quinto de los encuestados respondió que se debían fomentar ambos elementos en la misma medida. Resultan llamativas las diferencias que aparecen en esta pregunta al interior de los distintos segmentos socioeconómicos y también entre grupos etarios (Gráfico 7). Mientras el segmento socioeconómico alto y los más jóvenes favorecen la autonomía y la creatividad, el segmento bajo y los mayores le dan más importancia a la disciplina y el orden.

Gráfico 7: Disciplina y orden vs autonomía y creatividad según NSE, sexo y edad

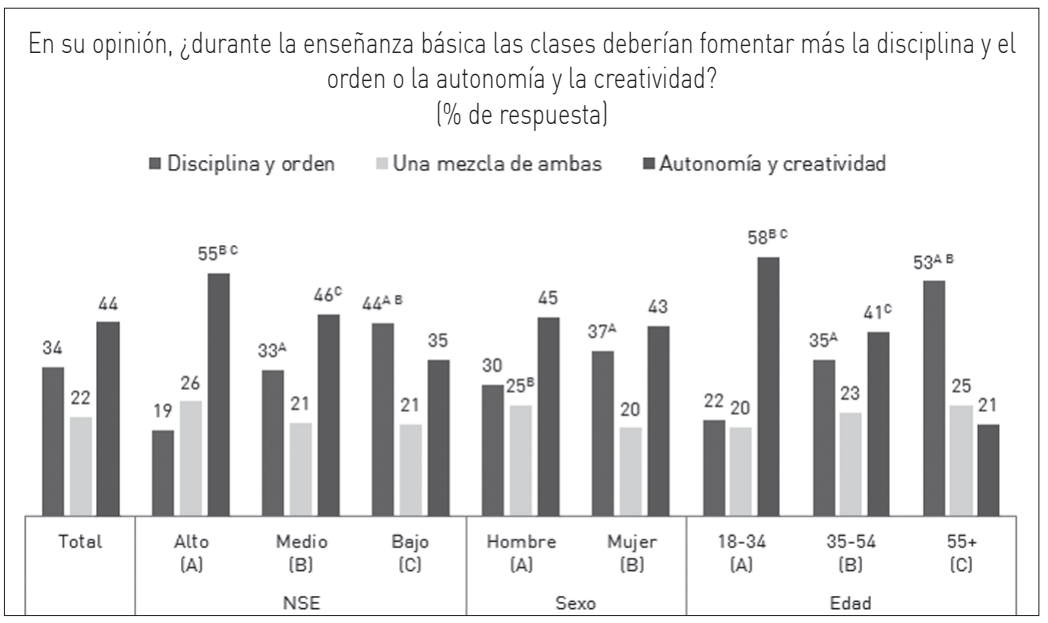

Diferencias basadas en test de significancia al .05 de dos colas. En cada valor se marca con un superíndice el segmento respecto de las que tiene una proporción significativamente mayor.

Frente a las otras dos tensiones evaluadas, las personas fueron aún más reacias a elegir una de las dos alternativas. Aunque haya muchos que prefieren enfocarse en el ámbito científico más que en el artístico, también hay muchos que se niegan a optar por uno de los dos (Gráfico 8). Asimismo, pese a una preferencia más marcada por el desarrollo social y emocional que por el desarrollo intelectual, más de un tercio de la muestra declara que se deberían fomentar ambos aspectos por igual. Este es el único caso en que el porcentaje de encuestados que se rehusó a inclinarse por una de las dos opciones supera los porcentajes asociados a cada uno de los polos. 
Gráfico 8: Tensiones en la escuela, porcentaje de respuesta intermedia

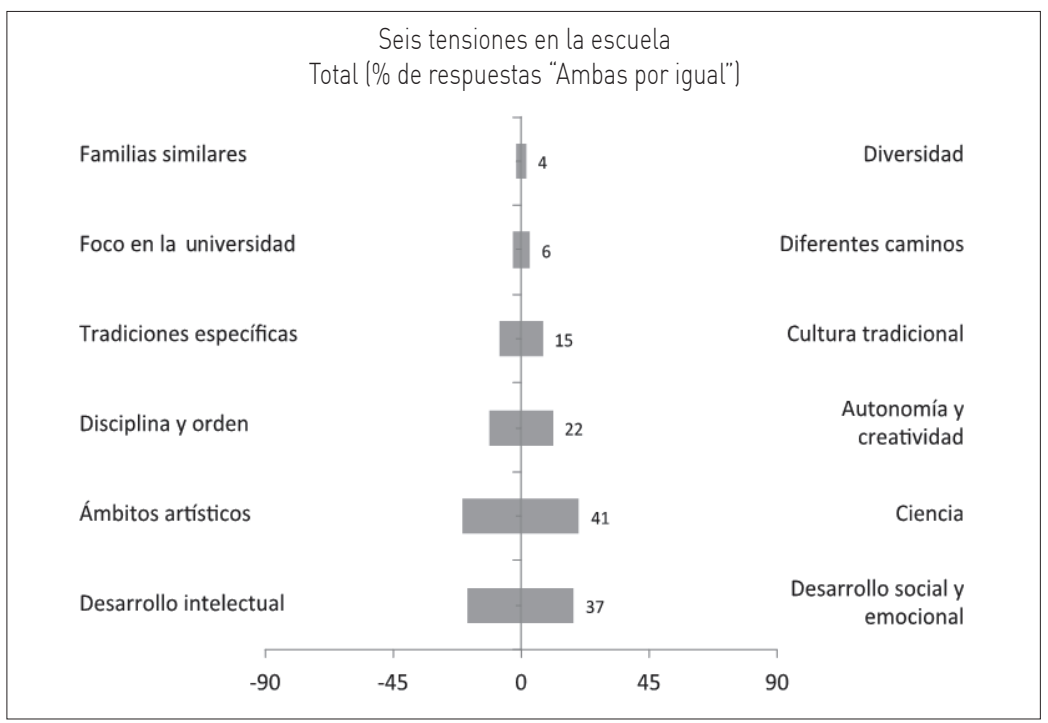

\section{Discusión}

A continuación discutimos los resultados recién reportados a la luz de las tres motivaciones del estudio que especificamos en la introducción: esclarecer los criterios o índices en virtud de los cuales la ciudadanía evalúa la calidad de la enseñanza básica; entender la importancia relativa que se le otorga a algunos de los objetivos de la enseñanza básica (estipulados por la ley); y evidenciar el modo en que los chilenos tendemos a posicionarnos frente a algunas tensiones y antinomias que pueden generarse al momento de tomar decisiones que afectan a la escuela desde distintos ámbitos. También nos referimos a otras temáticas, tales como el centralismo del currículo, el papel de la opinión pública en la educación y la brecha entre las escuelas que tenemos y las que nos gustaría tener. Esperamos que la discusión sirva para pensar y repensar políticas educativas en Chile, sobre todo en el contexto de la reforma educacional que está en marcha. 


\subsection{Excelencia docente}

La mayoría de los encuestados piensa que la calidad de la educación pasa por los profesores. Aquí la ciudadanía está alineada con los expertos en el área, quienes vienen señalando esto desde hace tiempo (Barber \& Mourshed, 2007; Bransford, Darling-Hammond \& LePage, 2005; Braslavsky, 1999; Bruner, 1996; Centro de Políticas Públicas, 2012; Cornejo, 1999; García, Escarbajal e Izquierdo, 2011; OCDE, 2005; OEI, 2008; Sahlberg, 2013; Torres, 1996; Villegas-Reimers, 1998). Aspectos como la infraestructura y el plan de estudios son ciertamente relevantes, pero nada se compara con la importancia capital de contar con profesionales de la enseñanza bien preparados para los desafíos de nuestro tiempo y nuestra sociedad. Esto es lo que la ciudadanía y los expertos demandan a coro; y debiera, por ende, ser uno de los ejes de cualquier reforma educacional, sobre todo si está inspirada por el mejoramiento de la calidad.

Se hace imperativo, además, que la pregunta por la excelencia docente empiece a ser considerada con seriedad en los círculos académicos, especialmente en las instituciones formadoras de profesores. Porque de poco sirve poner de relieve la importancia de contar con buenos profesores si no se ha discutido a fondo qué es exactamente un buen profesor. Por desgracia, la investigación en formación docente en Chile no ha incluido esta temática entre sus áreas prioritarias (véase Cisternas, 2011).

Algunos querrán invocar aquí los "estándares" (Mineduc, 2011). Se dirá: "Ya sabemos lo que es un buen profesor. Es cosa de mirar los estándares". Pero esto no es más que un argumento circular. Es precisamente para evaluar la adecuación de los estándares que debe hacerse la pregunta por la excelencia docente. En consecuencia, dicha pregunta no puede responderse apelando a los estándares. Para contestarla tenemos que partir por clarificar cuáles son las escuelas que queremos (esperamos que este reporte ayude) y luego, en virtud de ello, qué tipo o tipos de docentes responderían mejor a ese ideal.

La falta de un concepto claro, bien construido y bien consensuado de excelencia docente obstaculiza uno de los desafíos 
centrales de nuestro sistema educativo: revisar y corregir los defectos de los dispositivos de evaluación docente con que contamos (pues se hace difícil entender cómo evaluar a los profesores si no se tiene claridad respecto de qué es la buena docencia). Por mucho que en este campo se hayan hecho avances importantes en comparación con otros países (Manzi, González y Sun, 2011), resulta evidente que tenemos muchas tareas pendientes (véase, por ejemplo, Assaél y Pavez, 2008; Milicic, Rosas, Scharager, García y Godoy, 2008). Por lo pronto, si la capacidad de pensamiento reflexivo y la posesión de competencias prácticas son aspectos centrales para la buena docencia, es evidente que pruebas de alternativas como la Inicia, por ejemplo, son altamente inapropiadas.

\subsection{Rol de la escuela y formación integral}

Aun cuando la familia es vista como más responsable (que la escuela) en la mayoría de los ámbitos formativos, se reconoce claramente que ella sola no puede cumplir con todas las demandas de la tarea educativa, en particular con aquellas relacionadas con la formación intelectual. Además, hubo varias otras áreas que un grupo importante señaló como ámbitos de responsabilidad compartida: la formación valórica, la educación sexual, el cuidado de la salud, la educación ambiental y la convivencia. Aquí la opinión de la ciudadanía parece contrastar fuertemente con la idea de quienes sostienen que la escuela debiese hacerse cargo solo de la formación en las asignaturas.

En efecto, las respuestas de los encuestados apuntan, creemos, a que durante la enseñanza básica debiera producirse un proceso de desarrollo humano integral, en el cual lo intelectual o cognitivo es, sin duda, uno de los aspectos más importantes, pero de ningún modo el único importante. Así, por ejemplo, la polaridad entre la enseñanza de la ciencia y la enseñanza del arte, por un lado, y la polaridad entre el desarrollo socioemocional y el desarrollo intelectual, por otra, fueron las que más resistencia tuvieron por parte de la ciudadanía: la cantidad de personas que rehusó tomar partido por uno de los dos polos fue en ambos casos mucho mayor que para las otras polaridades propuestas. Adicionalmente, aspectos como el desarrollo de la autoestima, la responsabilidad y la buena convivencia tendieron a ser preferidos 
a habilidades académicas más "duras" como las relacionadas con el lenguaje y las matemáticas.

Lo anterior no quiere decir de ningún modo que los encuestados desconozcan o minimicen el valor del desarrollo cognitivo. Lo que sí se cuestiona es el énfasis que suele ponerse en ese ámbito, en desmedro de otros igualmente centrales. En este sentido, la ciudadanía parece estar alineada con los Objetivos Generales de la Educación Básica (expresados en la Ley General de Educación), entre los cuales se cuentan aspectos propios del desarrollo socioemocional y valórico.

Por otra parte, el contraste entre lo que la ciudadanía espera que pase en las escuelas y lo que de hecho pasa en la mayoría de ellas es aquí notorio. En parte por la influencia de las mediciones estandarizadas (tanto el SIMCE como la PSU), nuestras escuelas tienden a focalizarse en el desarrollo intelectual en desmedro de otras capacidades y actitudes que, sin embargo, la ciudadanía también quiere que la escuela desarrolle. Esta focalización casi exclusiva en la inteligencia simbólica es "un gigantesco problema de nuestro sistema educacional" (Rosas y Santa Cruz, 2013, p. 114), que limita severamente las posibilidades de desarrollo de los estudiantes y deja la tan difundida idea de "educación integral" reducida a poco más que una linda declaración de intenciones.

A nivel de política educativa, nos parece importante señalar dos situaciones. Primero, la formación pedagógica que reciben nuestros profesores en el ámbito del desarrollo socioemocional y valórico es muy escasa. Así, por ejemplo, en las mallas curriculares de las instituciones formativas no suele haber cursos dirigidos explícitamente a cómo desarrollar la autoestima de los niños o a cómo inculcar valores. Este es, creemos, uno de los desafíos más urgentes que tiene por delante la formación docente en nuestro país, al menos si se espera que el desarrollo humano integral tenga un lugar central en el sistema escolar.

En segundo lugar, pero no por eso menos relevante, la brecha entre lo que la ciudadanía espera de las escuelas y lo que ocurre realmente en ellas coincide con otro contraste interesante: aquel 
entre el bajo valor que le da la ciudadanía al SIMCE como indicador de calidad -recuérdese que apenas uno de cada diez encuestados (aproximadamente) lo menciona cuando se le pregunta por ello-y el alto valor que se le da a dicha prueba en buena parte de las políticas educativas de nuestro país. En particular, la visión de algunos de que los resultados del SIMCE por escuela deben darse a conocer a la población parece altamente cuestionable. A quién le interesa realmente esa información, y con qué fines se entrega, se vuelven preguntas muy relevantes si se considera que la inmensa mayoría de los chilenos parece no juzgar la calidad de una escuela en virtud de su desempeño en el SIMCE.

\subsection{Diversidad social}

Cuando se considera la gran segmentación social que existe en nuestro sistema escolar (véase, por ejemplo, Atria, 2012; Carrasco et al., 2014; Rosas y Santa Cruz, 2013) y la subsecuente homogeneidad que ello ha originado y perpetuado, llama bastante la atención que la inmensa mayoría de los encuestados, e independientemente de su situación socioeconómica, haya señalado que le parece mejor una escuela socialmente diversa que una en que los alumnos provengan de familias similares. Es posible, por cierto, que la pregunta se haya leído de distintas maneras. "Familias similares", por ejemplo, no significa necesariamente familias del mismo grupo socioeconómico. Asimismo, la expresión "diversidad social" podría haberse entendido como apuntando a diferencias de personalidad o de intereses, por ejemplo.

Sin embargo, tanto el contexto en el que se hizo la pregunta (el Chile después de la Revolución Pingüina), como la formulación de la misma, nos hacen pensar que, al menos para la mayoría de los encuestados, lo que se preguntaba estaba bastante claro. Asumiendo esto, ¿cómo se explica este nuevo contraste entre lo que la ciudadanía quisiera y la realidad de nuestras escuelas? Y, ¿qué tan confiable es el reporte de los encuestados en este punto? ¿Tenemos que creerle a los ciudadanos de un país cuyo sistema educacional está fuertemente segregado en grupos homogéneos cuando nos dicen que en su escuela ideal hay diversidad social? 
Nuestra respuesta es la siguiente. No importa tanto si cada uno de los participantes está siendo sincero o no. Lo que importa más es que aun si sus respuestas están marcadas por la deseabilidad social, por lo políticamente correcto, este resultado nos dice que la idea de una escuela diversa se ha establecido en Chile como lo deseable. Dicho de otro modo, la sociedad chilena actual tiende a reprobar la homogeneidad y la segregación en el sistema escolar, más allá de que a muchos padres pueda seguir gustándoles que sus hijos se eduquen solo con gente "como ellos", y más allá de que eviten expresar esa preferencia de manera abierta en una encuesta. Esa evitación no es más que un efecto de la presión de un contexto sociopolítico en el cual el valor de la diversidad ha ganado terreno.

\subsection{Currículo fijo y único}

Respecto del "centralismo" con que la ciudadanía tiende a pensar el currículo -al privilegiar un plan fijo y único para todo el país ${ }^{13}$ proponemos las siguientes explicaciones (todas posibles):

- La homogeneización del currículo puede percibirse como una medida para asegurar equidad. La idea básica detrás de esto es que todos tienen derecho a aprender lo mismo.

- La homogeneización del currículo puede percibirse como una medida para asegurar uniformidad cívica: hábitos e ideas que todos compartan en tanto ciudadanos chilenos. Esta hipótesis adquiere fuerza si se considera que la mayoría de los encuestados señaló, además, que la escuela debe preferir la enseñanza de la cultura tradicional chilena por sobre las tradiciones específicas de cada zona.

- Hay, en el mundo entero, una baja de confianza en la escuela como institución (OCDE, 2001). Esto podría traducirse en una desconfianza en la capacidad de las escuelas para decidir sus propios contenidos curriculares, lo que quedaría en manos del Gobierno. En esta línea, recuérdese que el 59\% de los encuestados señaló que el encargado de determinar lo que tienen que aprender los niños es el Gobierno (siendo esta la opción más referida), mientras que solo un $17 \%$ dijo que era la escuela la responsable de ello (aunque un 35\% aludió a los profesores).

13 Ver nota número 11 (acerca del uso de los términos "currículo" y "plan de estudios"). 
Dados los peligros bien sabidos del nacionalismo, nos parece relevante poner sobre la mesa la discusión de una visión como la consignada en el segundo punto, por mucho que la mayoría de la población pueda favorecerla. Hace ya más de una década que diversos autores han cuestionado el modelo de Estado-nación que ha sido fundamento y foco de la organización política de los países latinoamericanos, planteando la necesidad de desarrollar una noción renovada de ciudadanía que tome en cuenta tanto los procesos de integración impulsados por la globalización como el resurgimiento de las identidades locales, especialmente las indígenas (Assies, 2004; Bengoa, 2000; Hopenhayn, 2001; Hopenhayn, 2002, Stavenhagen, 2002). Respecto del caso chileno en particular, Bello (2011) señala que la idea de Estado-nación es un constructo cuyo origen se encuentra en el proyecto hegemónico de las elites, distante, por tanto, de los intereses y aspiraciones de la gran mayoría de la población arrastrada a ese proyecto.

Las repercusiones de esta discusión en el campo educativo $y$, específicamente, para las políticas curriculares, son evidentes y han sido ampliamente abordadas por estudiosos del tema (Hirmas y Blanco, 2009; Luna e Hirmas, 2005; Poblete y Galaz, 2007; Quintriqueo y Travers, 2009; Sánchez, 2001). Sin negar el derecho de la ciudadanía a influir en el currículo escolar (tema que abordamos a continuación), nos parece de la mayor importancia considerar críticamente la tendencia de los encuestados a preferir un currículo fijo y único. ¿No habrá al menos algunas áreas en las que la uniformidad cívica resulte poco beneficiosa, o incluso abiertamente perjudicial? Esta pregunta no puede omitirse ni trivializarse ni suponerse y a contestada. Si queremos vivir en una sociedad diversa e inclusiva, tenemos la responsabilidad de hacernos cargo de ella de manera explícita y participativa -especialmente si consideramos que la inmigración ha venido aumentando progresivamente durante los últimos años (Cano, Soffia $\&$ Martínez, 2009) y que, en todo caso, nuestra sociedad no está compuesta por una única nación. 


\subsection{Responsabilidad ciudadana}

Nos llama la atención la baja responsabilidad que se le otorga a la ciudadanía en lo que atañe a la decisión de lo que deben aprender los niños durante la enseñanza básica. Tal como señalamos en la introducción, es perfectamente posible que la ciudadanía no tenga conciencia de su derecho a influir en estas materias. De las muchas razones que podrían explicar esta falta de conciencia, una es que los chilenos tendemos quizá a pensar que las decisiones curriculares son un asunto meramente técnico, para el cual "hay especialistas". Y por supuesto que los hay: el diseño y la planificación curricular tienen sin duda una dimensión técnica. Por ello, aunque la voluntad ciudadana tenga siempre que considerarse, debe hacerse desde una posición crítico-reflexiva, reconociendo que la opinión pública no tiene fuerza de ley. Esto no puede oscurecer, sin embargo, ni la centralidad de lo que la ciudadanía quiere y espera ni la dimensión filosófica y éticopolítica que el debate necesariamente tiene en virtud del hecho de que cualquier currículo responde a un conjunto de fines (esto es, a una construcción social de lo deseable). Ciertamente, en Chile no tenemos, como bien han señalado Falabella y García-Huidobro (2013), "un horizonte normativo único y compartido sobre lo que la educación debe ser, sobre sus fines" (p. 7); es precisamente para construir ese horizonte, o para validar más de uno, que se requiere identificar a qué aspiramos como sociedad.

Aquí hemos querido avanzar en una descripción de la escuela básica que a la ciudadanía le gustaría que hubiese en Chile. Se trata, por cierto, de un trabajo exploratorio, muy incompleto. Hay muchas temáticas relevantes que ni siquiera alcanzamos a mencionar en este reporte, sea por descuido, falta de espacio o ignorancia; y la mayoría de las temáticas que sí abordamos requieren de un análisis más profundo. En varios puntos no hubo ni siquiera acuerdo entre los autores. Con todo, esperamos haber contribuido no solo a una representación parcial de la voluntad ciudadana en lo que respecta a la enseñanza básica, sino también al posicionamiento de problemáticas que, siendo trascendentales para las decisiones que atañen a nuestro sistema escolar, muchas veces se pasan por alto o, con algo de violencia simbólica, se suponen ya resueltas. 


\section{Referencias}

Abarca, V., Assaél, J., Brzovic, D., Caldichoury, J., Cornejo, R., González, J., Redondo, J., Sánchez, R., Sobarzo, M., Egaña, L., Reyes, L. y Santa Cruz, E. (2009). Documentos de trabajo OPECH. Santiago: OPECH.

Alfaro, F., Báez, C., Calcagni, M., Fernández, M., Fuentes, K., Sichen, H., Pérez, C., Mardónez, C., Neira, P., Salgado, N., Tijoux, M. y Winter, C. (2011). Calidad educativa. Lineamientos propositivos para una educación de calidad en Chile. Recuperado de http://es.scribd.com/ doc/63593100/Documento-Comision-Calidad-Educativa.

Assaél, J., y Pavez, J. (2008). La construcción e implementación del sistema de evaluación del desempeño docente chileno: principales tensiones y desafíos. Revista Iberoamericana de Evaluación Educativa, 1(2), 41-55.

Assies, W. (2004). Diversidad, Estado y democracia: unos apuntes. En Programa de las Naciones Unidas para el Desarrollo, La Democracia en América Latina. Hacia una democracia de ciudadanas y ciudadanos. Contribuciones para el debate (pp. 229-243). Buenos Aires: Alfaguara.

Atria, F. (2012). La mala educación. Ideas que inspiran al movimiento estudiantil. Santiago: Catalonia.

Barber, M., \& Mourshed, M. (2007). How the world's best-performing schools come out on top. Londres: McKinsey \& Company.

Bello, Á. (2011). Hegemonía, historia y pueblos indígenas en la formación del Estado-nación chileno. Recuperado de http://chitita.uta.cl/ cursos/2012-1/0000738/recursos/r-5.pdf

Bengoa, J. (2000). Emergencia indígena en América Latina. Santiago: Fondo de Cultura Económica.

Bransford, J., Darling-Hammond, L. \& LePage, P. (2005). Introduction. En L. Darling-Hammond \& J. Bransford (Eds.) Preparing teachers for a changing world. What teachers should learn and be able to do (pp. 1-39). San Francisco, CA: Jossey Bass.

Braslavsky, C. (1999). Bases, orientaciones y criterios para el diseño de programas de formación de profesores. Revista Iberoamericana de Educación, 19. Recuperado de http://www.rieoei.org/oeivirt/rie19a01. htm.

Bruner, J. (1996). The culture of education. Cambridge: Harvard University Press.

Cano, M., Soffia, M. y Martínez, J. (2009). Conocer para legislar y hacer política: los desafíos de Chile ante un nuevo escenario migratorio. Serie Población y Desarrollo CEPAL, 88. 
Carrasco, A., Contreras, D., Elacqua, G., Flores, C., Mizala, A., Santos, H., Torche, F. y Valenzuela, J. P. (2014). Hacia un sistema escolar más inclusivo: cómo reducir la segregación escolar en Chile. Informe de Políticas Públicas, 36. Recuperado de http://www.espaciopublico.cl/ media/publicaciones/archivos/25.pdf

Centro de Estudios Públicos. (2011). Estudio Nacional de Opinión Pública, junio-julio 2011. Recuperado de http://www.cepchile.cl/dms/lang_1/ doc_4844.html\#.U-vXNON5Pt8

Centro de Políticas Públicas. (2012). Propuestas para una carrera docente. Santiago: Centro de Políticas Públicas UC \& Elige Educar.

Cisternas, T. (2011). La investigación sobre formación docente en Chile. Territorios explorados e inexplorados. Calidad en la Educación, 35, 131-164.

Comité Técnico Asesor del Diálogo Nacional sobre la Modernización de la Educación Chilena. (1994). Los desafíos de la educación chilena frente al siglo 21. Informe de la Comisión Nacional para la Modernización de la Educación. Santiago: Editorial Universitaria.

Cornejo, J. (1999). Profesores que se inician en la docencia: algunas reflexiones al respecto desde América Latina. Revista Iberoamericana de Educación, 19, 51-100.

Cox, C. (2003). Las políticas educacionales de Chile en las últimas dos décadas del siglo XX. En C. Cox (Ed.), Políticas educacionales en el cambio de siglo. La reforma del sistema escolar de Chile. Santiago: Editorial Universitaria.

Delval, J. (1996). Los fines de la educación. Madrid: Siglo XXI de España Editores.

Dewey, J. (2007). The school and society. Nueva York: Cosimo Inc.

Eyzaguirre, B. y Le Foulon, B. (2001). La calidad de la educación chilena en cifras. Estudios Públicos, 84, 85-204.

Falabella, A. y García-Huidobro, J. (2013). Diálogos sobre los fines de la educación. En A. Falabella y J. García-Huidobro (Eds.), Los fines de la educación. Seminarios sobre gratuidad, lucro, justicia y democracia. Santiago: Ediciones UC.

García, A., Escarbajal, A. e Izquierdo, T. (2011). La formación del profesorado desde una perspectiva interdisciplinar. REIFOP, 14(1), 27-42.

Hirmas, C. y Blanco R. (2009). Educar en la diversidad cultural. Lecciones aprendidas desde la experiencia en América Latina. Docencia, 37, 45-55.

Hopenhayn, M. (2001). Viejas y nuevas formas de la ciudadanía. Revista de la CEPAL, 73, 117-128. 
Hopenhayn, M. (2002). Ciudadanía descentrada en tiempos de globalización. En W. Assies y T. Salman (Comps.), Ciudadanía, cultura política y reforma del Estado en América Latina. Zamora: Colegio de Michoacán.

Levinson, B., \& Holland, D. (1996). The Cultural production of the Educated Person. An Introduction. En B. Levinson, D. Foley \& D. Holland (Eds.), The cultural production of the educated person: Critical ethnographies of schooling (pp. 1-56). Albany: State University.

Luna, L. e Hirmas, C. (2005). Enfoques curriculares de educación intercultural en Chile: análisis para una propuesta de convivencia. VI Congreso Latinoamericano de Educación Intercultural Bilingüe, Santiago de Chile.

MacBeath, J. (2012). Future of teaching profession. Educational International Research Institute and University of Cambridge.

Manzi, J., González, R. y Sun, Y. (2011). La evaluación docente en Chile. Santiago: Mide UC.

Ministerio de Educación. (2011). Estándares orientadores para egresados de carreras de Pedagogía en Educación Básica. Estándares pedagógicos y disciplinarios. Gobierno de Chile. Recuperado de http:// historialimagen.files.wordpress.com/2011/10/libro-estandaresbasica. pdf

Milicic, N., Rosas, R., Scharager, J., García, M. R., y Godoy, C. (2008). Diseño, construcción y evaluación de una pauta de observación de videos para evaluar calidad del desempeño docente. Psykhe, 17(2), 79-90.

Núñez, I. (1996). Política social en educación: equidad, calidad, cualidad. Trabajo Social, 68, 37-51.

Organización para la Cooperación y Desarrollo Económicos. (2001). Schooling for tomorrow: What schools for the future? Paris: OCDE.

Organización para la Cooperación y Desarrollo Económicos. (2004). Revisión de políticas nacionales de educación. Chile. Paris: OCDE.

Organización para la Cooperación y Desarrollo Económicos. (2005). Teachers matter: Attracting, developing and retaining effective teachers. Paris: OCDE.

Organización de Estados Iberoamericanos. (2008). Metas educativas 2021. La educación que queremos para la generación de los bicentenarios. Texto elaborado como desarrollo al acuerdo alcanzado en la XVIII Conferencia Iberoamericana de Educación, celebrada en El Salvador.

Quintriqueo, S. y Mcginity, M. (2009). Implicancias de un modelo curricular monocultural en la construcción de la identidad sociocultural de alumnos/as mapuches de la IX Región de La Araucania, Chile. Estudios Pedagógicos 35(2), 173-188. 
Peña, C. (2013). Educación y ciudadanía: los problemas subyacentes. En A. Falabella y J. García-Huidobro (Eds.), Los fines de la educación. Seminarios sobre gratuidad, lucro, justicia y democracia (pp. 163-1719). Santiago: Ediciones UC.

Poblete, R., y Galaz, C. (2007). La identidad en la encrucijada: migración peruana y educación en el Chile de hoy. EMIGRA Working Papers, 3, 1-19.

Redondo, J., Descouvières, C. y Rojas, K. (2004). Equidad y calidad de la educación en Chile. Reflexiones e investigaciones de eficiencia de la educación obligatoria (1990-2001). Santiago: LOM.

Rosas, R. y Santa Cruz, C. (2013). Dime en qué colegio estudiaste y te diré qué CI tienes. Radiografía al desigual acceso al capital cognitivo en Chile. Santiago: Ediciones UC.

Sahlberg, P. (2013). El cambio educativo de Finlandia. ¿Qué puede aprender el mundo? Buenos Aires: Editorial Paidós SAICF.

Sánchez, M. (2001). Diseño curricular y educación intercultural bilingüe. Pensamiento Educativo, 29, 341-358.

Stavenhagen, R. (2002). Indigenous peoples and the state in Latin America: an ongoing debate. En R., Sieder (Ed.), Multiculturalism in Latin America. Indigenous rights, diversity and democracy (pp. 24-44). Londres: Institute of Latin American Studies.

Tedesco, J. C. (2000). Educar en la sociedad del conocimiento. Buenos Aires: Fondo de Cultura Económica.

Torres, R. M. (1996). Sin reforma de la formación docente no habrá reforma educativa. Perspectivas: Revista Trimestral de Educación Comparada, 3 , 481-503.

Valdebenito, L. (2011). La calidad de la educación en Chile: ¿un problema de concepto y praxis? Revisión del concepto calidad a partir de dos instancias de movilización estudiantil (2006 y 2011). CISMA, 1, 1-25.

Villegas-Reimers, E. (1998). The preparation of teachers in Latin America. Banco Mundial, Departamento de Desarrollo Humano.

Recibido: 15/08/2014

Aceptado: 16/01/2015 


\section{Anexo metodológico \\ Cálculo de nivel socioeconómico en encuesta telefónica}

El cálculo del nivel socioeconómico se realiza sobre la base de tres posibles fuentes de información, las cuales permiten identificar a todos los encuestados según alguno de los criterios que a continuación se describen y, al mismo tiempo, utilizar preguntas que sean sencillas de recabar a través del teléfono. La clasificación del nivel socioeconómico del entrevistado seguirá un algoritmo que consta de un máximo de tres pasos:

1. Principal: Se usan dos variables. La primera es nivel educativo del jefe de hogar y la segunda es ocupación del jefe de hogar. Las categorías para ambas variables se resumen a continuación.

a. Educación del jefe de hogar

- Sin educación formal.

- Básica incompleta.

- Básica completa.

- Media incompleta.

- Media completa.

- Técnica superior incompleta.

- Técnica superior completa.

- Universitaria incompleta.

- Universitaria completa.

- Postgrado, magíster, doctorado.

b. Ocupación del jefe de hogar. La ocupación del jefe de hogar es categorizada por el encuestador en alguno de los siguientes grupos:

- Trabajos menores ocasionales e informales.

- Oficio menor, obrero no calificado, jornalero, servicio doméstico con contrato.

- Obrero calificado, capataz, junior, microempresario.

- Empleado administrativo medio y bajo, vendedor, secretaria, técnico especializado, profesor. 
- Ejecutivo medio (subgerente), gerente general empresa mediana o pequeña, profesional carrera tradicional.

- Alto ejecutivo, gerente general de empresa grande, director o dueño de empresa mediana y grande.

- Dueña de casa.

- Estudiante.

- Rentista.

- Jubilado.

- Incapacitado.

- Desempleado.

Secundaria: Si en la ocupación del jefe de hogar, las respuestas son "jubilado", "dueña de casa", "rentista", "estudiante", "incapacitado" o "desempleado", se aplica una batería de 10 bienes, la cual incluye: computador, conexión a Internet, servicio doméstico, TV cable o satelital, teléfono celular, cámara de video, piscina (no desmontable), automóvil, casa de veraneo propia y cuenta corriente bancaria.

Terciaria: Si faltara información acerca de los bienes del hogar, como último recurso se clasifica a los hogares de acuerdo con el nivel educativo del encuestado. Esta última opción es la menos frecuente y deseada, por la inexactitud de la información, no obstante, suele ser aplicada menos del 2\% de las veces en un estudio de opinión. 


\section{Anexo 2 \\ Cuestionario}

Preguntas para introducir a las personas en el tema de educación

Mi nombre es (NOMBRE ENTREVISTADORA), y lo llamo desde la Universidad Católica de Chile para realizarle una breve encuesta que indaga acerca de sus opiniones sobre temas de educación en Chile. Toda la información que usted nos proporcione será tratada en forma estrictamente confidencial. Sus respuestas serán analizadas en conjunto con muchas otras y solo con fines de investigación científica. Usted tiene toda la libertad para no responder alguna pregunta o de concluir la entrevista si así lo desea. Si tiene cualquier consulta sobre esta entrevista le puedo entregar los datos de contacto del investigador principal del estudio.

¿Está usted dispuesta/o a continuar con la entrevista? Desde ya agradezco su colaboración.

Esta encuesta trata sobre la educación básica en Chile.

Temas de educación general

1. En general, ¿le pone atención a noticias referidas a educación en Chile?
a. Mucha atención
b. Bastante atención
c. Poca atención
d. Nada de atención
e. No sabe/No responde (NO LEER)

2. A su juicio, ¿qué elementos tiene que mostrar una escuela para decir que es de calidad? (ESPONTÁNEA)
a. Acreditación u origen de los profesores
b. Buenos profesores
c. Centrado en los niños
d. Comentarios de amigos o familiares
e. Experiencia propia 
f. Infraestructura

g. Plan de estudios/Programa educativo

h. Prestigio de la escuela

i. Puntaje PSU

j. Puntaje SIMCE

k. Reporte de los propios alumnos o exalumnos

1. Tipo de preparación que entrega para el trabajo

m. Visita al colegio (entrevistas con profesores o directivos)

n. Otros:

o. No sabe/No responde

Objetivos de la enseñanza básica

3. ¿Qué características se le vienen a la mente cuando piensa en un niño que ha recibido una educación básica de calidad? ¿Algo más? (ESPONTÁNEA, múltiple)

a. Conocimiento - artístico y/o musical

b. Conocimiento - culto/bien educado/acumulación de conocimiento

c. Conocimiento - ganas de saber y aprender

d. Conocimiento - historia y geografía

e. Lenguaje - escritura

f. Lenguaje - expresión oral/hablar bien

g. Lenguaje - inglés, idioma extranjero

h. Lenguaje - lectura u ortografía

i. Lenguaje - vocabulario

j. Razonamiento - competencias matemáticas

k. Razonamiento - formación científica

1. Razonamiento - pensamiento creativo/creatividad/innovación

m. Razonamiento - pensamiento crítico/autónomo

n. Salud física - ejercicio, alimentación, nutrición, cuidado del cuerpo

o. Salud mental - autoestima, autoconfianza, respeto por sí mismo

p. Salud mental - inteligencia emocional, manejo de frustración

q. Social - buen futuro

r. Social - capacidad para convivir/relacionarse/interactuar con otros 
s. Social - respeto por el medio ambiente

t. Social - respeto por los demás, tolerancia

u. Social - trabajo en equipo

v. Ética - buena conducta, que se porte bien

w. Ética - valores (que sea una buena persona)

x. Otros:

y. No sabe/No responde

4. ¿Usted piensa que es poco importante, importante, muy importante o imprescindible que durante la enseñanza básica se le enseñe a los niños...?

\begin{tabular}{l|l|l|l|l|l}
\hline & Imprescindible & $\begin{array}{c}\text { Muy } \\
\text { importante }\end{array}$ & Importante & $\begin{array}{c}\text { Poco } \\
\text { importante }\end{array}$ & $\begin{array}{c}\text { No sabe/no } \\
\text { contesta }\end{array}$ \\
\hline $\begin{array}{l}\text { A desarrollar una } \\
\text { autoestima positiva } \\
\text { y confianza en sí } \\
\text { mismos }\end{array}$ & & & & & \\
\hline $\begin{array}{l}\text { A conocer sus } \\
\text { derechos y } \\
\text { responsabilidades }\end{array}$ & & & & & \\
\hline $\begin{array}{l}\text { A respetar la } \\
\text { diversidad cultural, } \\
\text { religiosa y sexual }\end{array}$ & & & & & \\
\hline $\begin{array}{l}\text { A trabajar en equipo } \\
\text { A cuidar su salud }\end{array}$ & & & & & \\
\hline $\begin{array}{l}\text { A desarrollar la } \\
\text { curiosidad }\end{array}$ & & & & & \\
\hline $\begin{array}{l}\text { A usar información } \\
\text { de manera efectiva }\end{array}$ & & & & & \\
\hline
\end{tabular}


5. Ordene del más importante al menos importante los siguientes tres aspectos para desarrollar durante la enseñanza básica.

\begin{tabular}{l|l|l|l}
\hline & $1^{a}$ Opción & $2^{\text {a Opción }}$ & 3a Opción \\
\hline Autoestima positiva & & & \\
\hline Pensamiento lógico-matemático & & & \\
\hline Buena convivencia con otros & & & \\
\hline No sabe (NO LEER) & & & \\
\hline No responde (NO LEER) & & & \\
\hline
\end{tabular}

6. Ahora ordene del más importante al menos importante estos otros tres aspectos para desarrollar durante la enseñanza básica.

\begin{tabular}{l|l|l|l}
\hline & $1^{\text {a }}$ Opción & $2^{\mathrm{a}}$ Opción & $3^{\mathrm{a}}$ Opción \\
\hline Pensamiento reflexivo & & & \\
\hline Lectura y escritura & & & \\
\hline Responsabilidad & & & \\
\hline No sabe (NO LEER) & & & \\
\hline No responde (NO LEER) & & & \\
\hline
\end{tabular}

Importancia de asignaturas en la enseñanza básica

7. De las asignaturas que se imparten actualmente en la enseñanza básica, ¿cuáles cree usted que deberían ser las más importantes? (ESPONTÁNEA, respuesta múltiple)
a. Artes Visuales
b. Ciencias Naturales
c. Educación Física y Salud
d. Historia, Geografía y Ciencias Sociales
e. Idioma Extranjero
f. Lenguaje y Comunicación
g. Matemática
h. Música
i. Religión
j. Tecnología
k. Todas son importantes
1. Otra:
m. No sabe/No responde 
Rol del Estado y la familia en ámbitos educativos

8. ¿Usted cree que el plan de estudios para la enseñanza básica debería ser fijo y único para todo el país, o debiera permitir que cada escuela construyera su propio plan?
a. Currículo fijo y único
b. Cada colegio puede construir su propio plan
c. Una mezcla de ambos (NO LEER)
d. No sabe/No responde (NO LEER)

9. ¿Quién debería ser el encargado de determinar lo que tienen que aprender los niños durante su enseñanza básica? ¿Alguien más? (ESPONTÁNEA, respuesta múltiple)
a. La ciudadanía/todos los chilenos
b. El Gobierno
c. Estado (pasar a pregunta 10)
d. Ministerio de Educación
e. Escuela/colegio
f. Familia/padres/apoderados
g. Iglesia
h. Los mismos niños
i. Los profesores
j. No sabe/No responde

10. (Solo si contesta "C" en P9) Cuando menciona "Estado", ise refiere al Gobierno o a la ciudadanía?
a. Gobierno
b. Ciudadanía
c. No sabe/No responde
d. Otro 
11. ¿Y qué tan responsables es... en la decisión de lo que deben aprender los niños durante su enseñanza básica?

\begin{tabular}{l|l|l|l|l}
\hline & Muy responsable & Responsable & $\begin{array}{c}\text { Nada } \\
\text { responsable }\end{array}$ & NS/NR \\
\hline La ciudadanía & & & & \\
\hline $\begin{array}{l}\text { El Ministerio de } \\
\text { Educación }\end{array}$ & & & & \\
\hline La familia & & & & \\
\hline La iglesia & & & & \\
\hline
\end{tabular}

Relación de la familia con la escuela

Ahora le preguntaremos sobre la relación que tiene una familia con la escuela a la que manda a sus hijos.

12. En los siguientes ámbitos relacionados con la educación del niño, ¿quién debería ser más responsable, la familia o la escuela?

\begin{tabular}{|c|c|c|c|c|c|}
\hline & $\begin{array}{c}\text { Más en la } \\
\text { escuela }\end{array}$ & $\begin{array}{l}\text { Más en la } \\
\text { familia }\end{array}$ & $\begin{array}{c}\text { En ambos } \\
\text { por igual } \\
\text { (NO LEER) }\end{array}$ & $\begin{array}{l}\text { Ninguno } \\
\text { (NO LEER) }\end{array}$ & $\begin{array}{c}\text { No sabe/No } \\
\text { responde } \\
\text { (NO LEER) }\end{array}$ \\
\hline \multicolumn{6}{|l|}{ Educación sexual } \\
\hline \multicolumn{6}{|l|}{ Política } \\
\hline \multicolumn{6}{|l|}{ Religión } \\
\hline \multicolumn{6}{|l|}{ Formación ética o valórica } \\
\hline \multicolumn{6}{|l|}{ Educación ambiental } \\
\hline \multicolumn{6}{|l|}{ Educación económica } \\
\hline \multicolumn{6}{|l|}{$\begin{array}{l}\text { Cuidado de la salud física y } \\
\text { mental }\end{array}$} \\
\hline \multicolumn{6}{|l|}{ Formación intelectual } \\
\hline Convivencia con otros niños & & & & & \\
\hline
\end{tabular}


Objetivos y funciones de la escuela

13. ¿Y qué tanto debería influir la escuela básica en...?

\begin{tabular}{l|l|l|l|l}
\hline & Mucho & Algo & Poco & $\begin{array}{c}\text { No sabe/No responde } \\
\text { (NO LEER) }\end{array}$ \\
\hline La formación valórica de los niños & & & & \\
\hline La formación de lazos y redes & & & & \\
\hline La preparación de la fuerza laboral del país & & & & \\
\hline La formación cívica & & & & \\
\hline La valoración de la democracia & & & & \\
\hline La preparación de los niños para acceder a & & & & \\
\hline la educación superior & & & & \\
\hline El patriotismo de los niños & & & & \\
\hline El rescate de tradiciones de pueblos & & & & \\
\hline riginarios & & & & \\
\hline La disminución de la desigualdad social & & & & \\
\hline
\end{tabular}

Tensiones dentro de la escuela

A continuación le planteamos algunas tensiones que puede haber en la enseñanza básica. Le pediré que me diga cuál es la alternativa que le parece mejor.

14. En su opinión, ¿durante la enseñanza básica las clases deberían fomentar más la disciplina y el orden o la autonomía y la creatividad?
a. Disciplina y orden
b. Autonomía y creatividad
c. Ambas cosas (NO LEER)
d. No sabe/No responde (NO LEER)

15. ¿Las clases deberían fomentar más el desarrollo intelectual o el desarrollo social y emocional de los niños?
a. Desarrollo intelectual
b. Desarrollo social y emocional
c. Una mezcla de ambas (NO LEER)
d. No sabe/No responde (NO LEER) 
16. ¿La escuela debería fomentar más la enseñanza de la cultura tradicional chilena en general o de tradiciones específicas de la zona en que se encuentra cada escuela?
a. Cultura tradicional chilena
b. Tradiciones específicas
c. Una mezcla de ambas (NO LEER)
d. No sabe/No responde (NO LEER)

17. ¿Las clases deberían enfocarse más en la enseñanza de las ciencias o en ámbitos más artísticos?
a. Ciencia
b. Ámbitos artísticos
c. Una mezcla de ambas (NO LEER)
d. No sabe/No responde (NO LEER)

18. ¿La enseñanza básica debiera enfocarse en que los niños entren a la universidad o en mostrar diferentes caminos en los que la universidad es solo uno de ellos?
a. Foco en la universidad
b. Diferentes caminos
c. Una mezcla de ambos (NO LEER)
d. No sabe/No responde (NO LEER)

19. ¿Le parece mejor una escuela cuyos alumnos provengan de familias similares o una escuela en que haya diversidad social?
a. Familias similares
b. Diversidad
c. Una mezcla de ambos (NO LEER)
d. Depende del tipo de parecido/diversidad (NO LEER)
e. No sabe/No responde (NO LEER)

\section{Caracterización sociodemográfica}

20. Registre el sexo del entrevistado
a. Masculino
b. Femenino 
21. ¿Cuál es su edad?

a. años

22. ¿Cuántos hijos tiene?
a. hijos
b. No tengo hijos

23. (Si dice tener hijos) ¿Alguno de sus hijos está cursando actualmente la educación básica?
a. Sí
b. No
c. No sabe/No responde (NO LEER)

24. (Si dice tener hijos en educación básica) ¿En qué tipo de colegio tiene a sus hijos que cursan educación básica?

Si tiene varios hijos en distintos tipos de colegio, dígame el tipo de colegio del menor
a. Municipal/estatal
b. Particular subvencionado
c. Particular pagado
d. No sabe/No responde (NO LEER)

25. (Si dice tener hijos en educación básica) ¿Qué tanto se reúne con otros apoderados de la escuela?
a. Una vez al mes o más
b. Una vez al semestre
c. Una vez al año o menos
d. Nunca me reúno con otros apoderados
e. No sabe/No responde (NO LEER)

26. (Si dice tener hijos en educación básica) ¿Cree que ese colegio ofrece una educación de calidad?

Si tiene varios hijos en distintos tipos de colegio, dígame el tipo de colegio del menor.
a. Sí
b. No
c. No sabe/No responde 


\section{Caracterización sociodemográfica}

27. Para finalizar le haremos algunas preguntas con fines estadísticos. ¿Me podría decir cuál es su nivel de educación? (Esperar respuesta y clasificar)
a. Sin educación
b. Básica incompleta
c. Básica completa
d. Media incompleta
e. Media completa
f. Técnica superior incompleta
g. Técnica superior completa
h. Universitaria incompleta ( 1 a 3 años de estudio)
i. Universitaria completa
j. Posgrado, magíster, doctorado

28. ¿A qué tipo de colegio acudió usted durante su educación básica?
a. Municipal/estatal
b. Particular subvencionado
c. Particular pagado
d. No sabe/No responde (NO LEER)

29. En la actualidad, ¿usted trabaja remuneradamente?
a. Sí
b. No
c. No sabe (NO LEER)
d. No responde (NO LEER)

30. ¿Cuál es el nivel de educación que alcanzó la persona que aporta el ingreso principal de este hogar? (Esperar respuesta y clasificar)
a. Sin educación
b. Básica incompleta
c. Básica completa
d. Media incompleta
e. Media completa
f. Técnica superior incompleta
g. Técnica superior completa
h. Universitaria incompleta (1 a 3 años de estudio) 
i. Universitaria completa

j. Posgrado, magíster, doctorado

31. ¿Cuál es la ocupación del jefe de hogar en el que usted vive? (Esperar respuesta y escribir)

a.

32. Encuestador: clasifique la profesión o trabajo de la persona que aporta el principal ingreso de este hogar
a. Trabajos menores ocasionales e informales
b. Oficio menor, obrero no calificado, jornalero, servicio doméstico con contrato
c. Obrero calificado, capataz, junior, microempresario
d. Empleado administrativo medio y bajo, vendedor, secretaria, técnico especializado, profesor
e. Ejecutivo medio (subgerente), gerente general empresa mediana o pequeña, profesional carrera tradicional
f. Alto ejecutivo, gerente general de empresa grande, director o dueño de empresa mediana y grande
g. Dueña de casa
h. Estudiante
i. Rentista
j. Jubilado
k. Incapacitado
l. Desempleado 
33. (Sólo si respondió alternativas g a l) ¿Cuáles de los siguientes bienes o servicios poseen en este hogar?

\begin{tabular}{l|l|l|l}
\hline Computador & Sí & No & No sabe/No responde (NO LEER) \\
\hline Conexión a Internet & & & \\
\hline Servicio doméstico & & & \\
\hline TV cable o satelital & & & \\
\hline Teléfono celular & & & \\
\hline Cámara de video & & & \\
\hline Piscina (no desmontable) & & & \\
\hline Automóvil & & & \\
\hline Casa de veraneo propia & & & \\
\hline Cuenta corriente bancaria & & & \\
\hline
\end{tabular}

Muchas gracias por su tiempo y colaboración. 